University of Nebraska - Lincoln

DigitalCommons@University of Nebraska - Lincoln

USDA National Wildlife Research Center - Staff Publications
U.S. Department of Agriculture: Animal and Plant Health Inspection Service

August 2004

\title{
Ex post economic analysis of reproduction-monitoring and predator-removal variables associated with protection of the endangered California least tern
}

\author{
Stephanie A. Shwiff \\ Ray T. Sterner \\ USDA, Wildlife Services, National Wildlife Research Center \\ John W. Turman \\ USDA/APHIS/WS National Wildlife Research Center \\ Brian D. Foster \\ USDA, Wildlife Services, National Wildlife Research Center
}

USDA/APHIS/WS National Wildlife Research Center, stephanie.a.shwiff@aphis.usda.gov

Follow this and additional works at: https://digitalcommons.unl.edu/icwdm_usdanwrc

Part of the Environmental Sciences Commons

Shwiff, Stephanie A.; Sterner, Ray T.; Turman, John W.; and Foster, Brian D., "Ex post economic analysis of reproduction-monitoring and predator-removal variables associated with protection of the endangered California least tern" (2004). USDA National Wildlife Research Center - Staff Publications. 55.

https://digitalcommons.unl.edu/icwdm_usdanwrc/55

This Article is brought to you for free and open access by the U.S. Department of Agriculture: Animal and Plant Health Inspection Service at DigitalCommons@University of Nebraska - Lincoln. It has been accepted for inclusion in USDA National Wildlife Research Center - Staff Publications by an authorized administrator of DigitalCommons@University of Nebraska - Lincoln. 


\title{
ANALYSIS \\ Ex post economic analysis of reproduction-monitoring and predator-removal variables associated with protection of the endangered California least tern
}

\author{
Stephanie A. Shwiff ${ }^{\mathrm{a}, *}$, Ray T. Sterner ${ }^{\mathrm{a}}$, John W. Turman ${ }^{\mathrm{b}}$, Brian D. Foster ${ }^{\mathrm{c}}$ \\ ${ }^{\mathrm{a}}$ USDA, Wildlife Services, National Wildlife Research Center, 4101 LaPorte Ave, Fort Collins, CO 80521-2154, United States \\ ${ }^{\mathrm{b}}$ USDA, Wildlife Services, 9380 Bond Avenue, El Cajon, CA 92021, United States \\ ${ }^{\mathrm{c}}$ The Zoological Society of San Diego, P.O. Box 120551, San Diego CA 92112-0551, United States
}

Received 1 August 2003; received in revised form 20 May 2004; accepted 10 August 2004

Available online 3 February 2005

\begin{abstract}
Important nest sites for the endangered California least tern remain at the U.S. Marine Corps Base, Camp Pendleton, CA; these terns comprise approximately $17 \%$ of the state's breeding population. This paper presents an empirical analysis of annual, fixed-cost budgets expended for reproduction-monitoring and predator-removal activities to protect this shorebird. The ex post study covered the inclusive 7-year period between 1995 and 2001. Separate regression analyses were computed using 15 biological $\left(X_{\mathrm{B}}\right)$, economic $\left(X_{\mathrm{E}}\right)$, and meteorological $\left(X_{\mathrm{M}}\right)$ variables. In separate analyses, 14 of these variables served as independent variables to predict each of four dependent tern observation variables (i.e., $Y_{\text {nests }}, Y_{\text {eggs }}, Y_{\text {fledglings }}$, and $Y_{\text {adults }}$ ), with certain variables "lagged" (i.e., regressed after fixed intervals) to compensate for delayed effects of predator management. Mean net current annual reproduction-monitoring and predator-removal budgets were US $\$ 80,115$ and US $\$ 78,178$, respectively; annual fiscal data were converted to "proxy" variables of personnel time (h) for analysis of economic effects. Mean time spent in reproduction-monitoring $(3.12 \mathrm{~h} /$ day $)$ and predator-removal activities $(6.96 \mathrm{~h} /$ day $)$ differed greatly. Expenditures for both reproduction-monitoring and predator-removal staff hours were associated with greater counts of tern eggs and adults, with increased monitoring hours predictive of finding more tern nests and fledglings and increased predator-removal hours linked with fewer fledgling counts. No meteorological variables predicted any dependent variable. Economic issues involved in recovery of threatened and endangered species (TS/ES) are discussed.
\end{abstract}

Published by Elsevier B.V.

Keywords: Endangered species; California least tern; Predator management; Reproduction monitoring; Regression analysis; Economics

* Corresponding author. Tel.: +1970266 6150; fax: +1970266 6157.

E-mail address: stephanie.a.shwiff@aphis.usda.gov (S.A. Shwiff).

\section{Introduction}

In the United States, the Endangered Species Act, perhaps more than any other single legislative event,

0921-8009/\$ - see front matter. Published by Elsevier B.V.

doi:10.1016/j.ecolecon.2004.08.008 
reinforced the idea of qualitative and quantitative valuations for rare animals and plants (see U.S. Department of the Interior, 1973). Still, few studies have attempted to empirically measure the effectiveness of fiscal variables on the production of threatened and endangered species (TS/ES).

The California least tern (Sterna antillarium brownii) was one of the originally listed TS (sic ES) in the United States (Federal Register 35:8491$8498,1970)$. This small $(<25 \mathrm{~cm})$, ground-nesting seabird inhabits the Pacific Coast of Central and North America, migrating north and south annually to nest during the spring and summer months in colonies on coastal dunes and beaches from southern Baja to San Francisco, CA (Bent, 1921; Grinnell and Miller, 1944). A century ago, breeding populations numbered in the thousands (Secrist, 1915), but by the time of its listing, the total known population numbered between 300 and 600 nesting pairs (U.S. Department of the Interior, 1973). Predation, coastal development, and human recreation have impacted recruitment, while dredging, filling, and water pollution continue to degrade offshore fisheries (see Butchko and Small, 1992; Caffrey, 1994).
Important nest sites of the California least tern remain at the U.S. Marine Corps Base, Camp Pendleton. These terns comprise approximately $17 \%$ of the total California breeding population (Caffrey, 1994). In recent years, fixed-cost agreements have been effected here to monitor reproduction and to limit predation. Reproduction monitoring has delineated tern reproductive success, has improved surveillance, and has guided predator management activities. Similarly, predator management has been practiced since 1988 (see Avery et al., 1995; Butchko, 1990; Butchko and Small, 1992).

Here, we describe an ex post study of monetary expenditures to protect the California least tern at Camp Pendleton. Seven years (1995-2001) of annual fixed-cost budgets for reproduction-monitoring and predator-management activities were analyzed. Descriptive, correlation, and regression statistics were used to characterize the influence of 14 biological, economic, and meteorological variables (e.g., predators removed, monitoring hour, precipitation) upon four dependent variables of tern reproduction (i.e., nests, eggs, fledglings, and adults).

\section{CAMP PENDELTON, CALIFORNIA}

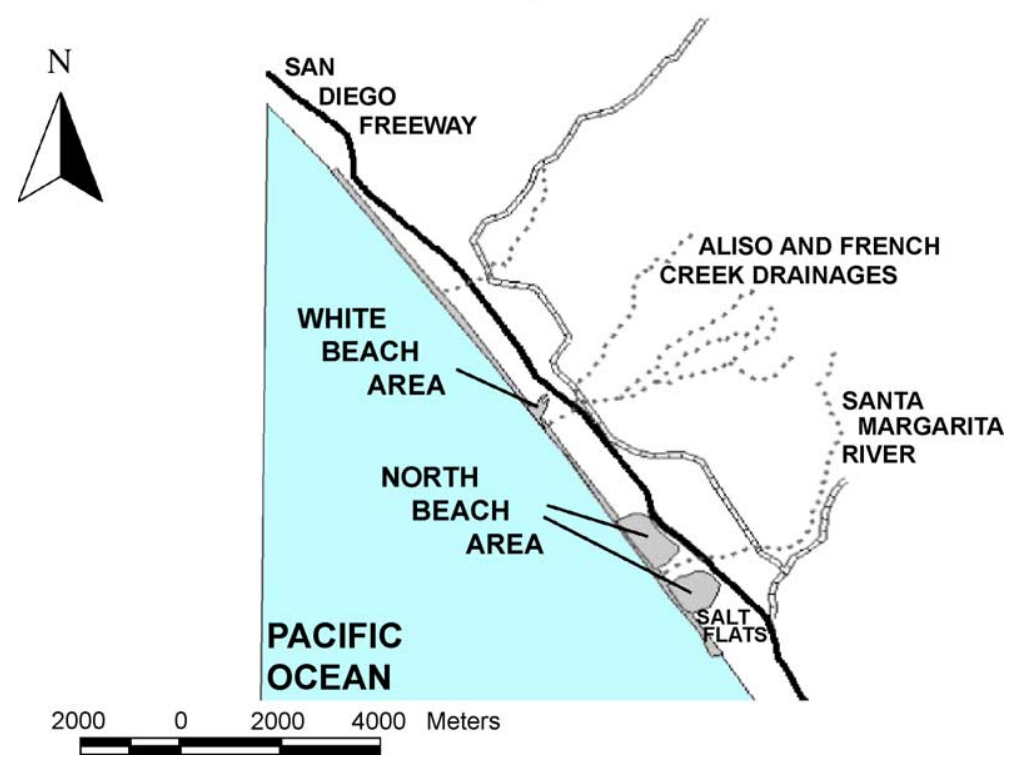

Fig. 1. Map of Camp Pendleton showing main nesting areas of the California least tern. 


\section{Approach and methods}

\subsection{Camp Pendleton site}

The U.S. Marine Corps Base, Camp Pendleton, CA is a main amphibious training center located in northwest San Diego County. The base encompasses $\approx 50,000 \mathrm{ha}$, with $\approx 27 \mathrm{~km}$ of coastline along the Pacific Ocean (Fig. 1). California least terns show annual nesting fidelity to the site, with some data suggesting that over $70 \%$ of adults return to the same nest areas annually (Caffrey, 1994; Massey and Fancher, 1989).

Two main nest areas for the terns on this coastline are located on beaches near the mouths of two freshwater drainages, Aliso/French Creeks and Santa Margarita Estuary. The Aliso/French Creek area, termed White Beach, is composed of a $\approx 20$ - to 40 $\mathrm{m}$ by $\approx 4-\mathrm{km}$ stretch of sand that is partially enclosed with a $7.5 \times 15.2 \mathrm{~cm}$ lattice-type fence $(183 \mathrm{~cm}$ high $)$, having a base of wire mesh. The fence deters human encroachment and obstructs chick dispersal. The Santa Margarita Estuary area consists of two main nesting locations: North Beach and Salt Flats. North Beach measures $\approx 60-90 \mathrm{~m}$ by $\approx 0.75 \mathrm{~km}$ and consists of sandy beachfront dunes with some grasses. It is also partially fenced to prevent human encroachment and chick dispersal. Salt Flats consists of $\approx 75$ ha, unfenced area of scattered marsh vegetation; main nest areas are limited to a $\approx 150 \times 120 \mathrm{~m}$ area adjacent to the River and $\mathrm{a} \approx 60 \times 10 \mathrm{~m}$ "island" created from dredged sediments slightly inland of the beach and south of the estuary.

Arrival and departure dates of adult terns at Camp Pendleton vary little among years. For the 1995-2001 interval comprising the current analysis, arrival dates occurred between April 18 and 20 and departure dates were from August 22 to September 9.

\subsection{General procedures and data sets}

Table 1 provides a description of the dependent and independent variables in the system.

\subsubsection{Biological data}

The two forms of biological information were reproduction-monitoring data and predator-removal data. Reproduction-monitoring data were obtained
Table 1

Description of dependent and independent variables

\begin{tabular}{|c|c|c|}
\hline Variable & Variable name & Description \\
\hline \multirow[t]{4}{*}{$Y$ or $X_{\mathrm{B}}$} & adults & $\begin{array}{l}\text { the number of adult terns } \\
\text { observed }\end{array}$ \\
\hline & totnests & $\begin{array}{l}\text { the number of total tern nests } \\
\text { observed }\end{array}$ \\
\hline & eggs & the number of tern eggs observed \\
\hline & fledglings & $\begin{array}{l}\text { the number of tern fledglings } \\
\text { observed }\end{array}$ \\
\hline \multirow[t]{4}{*}{$X_{\mathrm{B}}$} & actnests & the number of active tern nests \\
\hline & adincub & $\begin{array}{l}\text { the number of adults incubating } \\
\text { eggs }\end{array}$ \\
\hline & badout & $\begin{array}{l}1 \text { if there was a bad event, and } \\
0 \text { otherwise }\end{array}$ \\
\hline & totalpred & the number of predators removed \\
\hline \multirow[t]{3}{*}{$X_{\mathrm{E}}$} & predremhrs & $\begin{array}{l}\text { the number of hours spent on site } \\
\text { by predator-removal staff }\end{array}$ \\
\hline & monitoringhrs & $\begin{array}{l}\text { the number of hours spent on site } \\
\text { by monitoring staff }\end{array}$ \\
\hline & totalhrs & $\begin{array}{l}\text { predator-removal hours plus } \\
\text { monitoring hours }\end{array}$ \\
\hline \multirow[t]{4}{*}{$X_{\mathrm{M}}$} & precip & $\begin{array}{l}\text { the amount of precipitation in } \\
\text { centimeters }\end{array}$ \\
\hline & avgtemp & $\begin{array}{l}\text { the average daily temperature } \\
\text { in Celsius }\end{array}$ \\
\hline & avgwspd & $\begin{array}{l}\text { the average daily wind speed in } \\
\text { kilometers per hour }\end{array}$ \\
\hline & dewpt & the dew point in degrees Celsius \\
\hline
\end{tabular}

from detailed reports of reimbursable funds agreements between the U.S. Department of the Navy, Southwest Division, Naval Facilities Engineering Command (NAVFAENGCOM), San Diego, CA and The Zoological Society of San Diego, San Diego, CA (see Foster, 1996, 1997, 1998, 1999, 2000, 2001, 2002). Predator-removal data were obtained from reports of reimbursable funds agreements between NAVFAENGCOM, the U.S. Department of Agriculture, Wildlife Services (USDA/WS), El Cajon, CA, and the USDA/WS Management Information System.

Reproduction monitoring involved the identification of new nests, eggs, and fledglings. Nesting areas were lined off in $15 \times 15$ or $30 \times 30$ m numbered grids. This allowed for determinations of nest construction, distribution, egg-laying chronology, clutch size, incubation, as well as adult, chick, and fledgling countsrecords of reproductive success and mortality. Observers carefully walked back and forth among grids recording measurements on each search date. They also noted predator sign or activity to assist with 
predator-removal efforts. Typically, observers made intensive searches of colony areas multiple times per week, with numbers of searches dependent upon funding.

Four variables were analyzed as dependent variables (i.e., total nests, total eggs, total fledglings, and total adult terns). During incubation, male and female terns tenaciously stay on the nests (eggs). Thus, numbers of active nests (Actnests) and numbers of adult terns incubating nests (Adincub) were chosen as key measures of nesting activity. To reflect deleterious events upon reproduction, we generated a dichotomous variable of nest, egg, fledgling, or adult bird destruction (Bad Outcome); this served as a gross predictor of weather, predator, or other induced loss.

Predator removal to improve reproductive success of the terns was a continuous, 7-day/week activity. Predator removal began about 1 month before arrival of the terns and continued until their departure (i.e., essentially March-August inclusive). Predator removal sought to create a "predator-free" zone around the combined nesting areas. Although the exact size of this "zone" varied both within and between years depending upon animal behavior, predator removal was intensely practiced at all nesting areas and within $\approx 1-4 \mathrm{~km}$ approaches (i.e., drainages) leading to these areas.

The techniques used for predator removal included: avicides (i.e., 3-chloro- $p$-toluidine hydrochloride), bal-chatri traps, cage traps, conibear traps, pole traps, padded-jaw leg-hold traps, snares, spotlighting, and shooting (see Butchko, 1990; Butchko and Small, 1992; Hyngstrom et al., 1994). Terrestrial mammalian predators were euthanized at the time of capture, but raptor species were translocated out of the area, and if injured, these birds were treated by a local raptor rehabilitation center.

Diverse species of avian and mammalian predators/ scavengers were removed, with total predator numbers (Totalpred) used as an independent variable. An example of predator-removal data is shown in Table 2. In 1999, a total of 312 predators/scavengers, representing 11 mammalian and 14 avian species, was removed. This reflected 3105 cage trap-nights, 1438 padded-jaw leg-hold trap-nights, and 589 raptor trapnights (English, 1999).
Table 2

Representative summary of predator removals-1999

\begin{tabular}{|c|c|c|}
\hline Species & Scientific name & Number \\
\hline American crow & Corvus brachyrhynchos & 41 \\
\hline American kestrel & Falco sparverius & 5 \\
\hline Barn owl $^{\mathrm{a}}$ & Tyto alba & 36 \\
\hline $\begin{array}{l}\text { Black-crowned } \\
\text { night heron }\end{array}$ & Nycticorax nycticorax & 1 \\
\hline Bobcat & Felis rufus & 12 \\
\hline $\begin{array}{l}\text { California ground } \\
\text { squirrel }\end{array}$ & Spermophilus beecheyi & 64 \\
\hline Common raven & Corvus corax & 30 \\
\hline Cooper's hawk & Accipiter cooperi & 1 \\
\hline Coyote & Canis latrans & 20 \\
\hline Feral cat & Felis catus & 5 \\
\hline Feral dog ${ }^{b}$ & Canis familiaris & 1 \\
\hline Gopher snake ${ }^{b}$ & $\begin{array}{l}\text { Pituophis catenifer } \\
\text { annectens }\end{array}$ & 1 \\
\hline Great blue heron & Ardea herodias & 3 \\
\hline Great horned owl ${ }^{\mathrm{a}}$ & Bubo virginianus & 8 \\
\hline Long-eared owl ${ }^{\mathrm{a}}$ & Asio otus & 1 \\
\hline Long-tailed weasel & Mustela frenata & 2 \\
\hline Meadow lark & Sturnella neglecta & 1 \\
\hline Northern harrier hawk & Circus cyaneus & 1 \\
\hline Peregrin falcon & Falco perigrenus & 1 \\
\hline Raccoon & Procyon lotor & 5 \\
\hline Red-tailed hawk & Buteo jamaicansis & 1 \\
\hline $\begin{array}{l}\text { Southern Pacific } \\
\text { rattlesnake }\end{array}$ & $\begin{array}{l}\text { Crotalus viridis } \\
\text { oregamus }\end{array}$ & 1 \\
\hline Striped skunk & Mephitis mephitis & 4 \\
\hline Western gull & Larus occidentalis & 5 \\
\hline Virginia opossum & Didelphis virginiana & 31 \\
\hline
\end{tabular}

${ }^{a}$ All or some of these species taken to a wildlife rehabilitation center.

b All of these species were released on site or relocated to another part of Camp Pendleton.

\subsubsection{Economic data}

Annual fiscal budgets for both reproduction-monitoring and predator-removal agreements were provided by NAVFAENGCOM. Budget structures for the agreements differed. A typical breakdown for the reproduction-monitoring contracts was: Monitoring labor $(\approx 55 \%)$, report preparation $(\approx 10 \%)$, project coordination $(\approx 9 \%)$, site preparation $(\approx 3 \%)$, data entry $(\approx 3 \%)$, material and supplies $(\approx 2 \%)$, avianpredator rehabilitation $(\approx 1 \%)$, overhead $(\approx 17 \%)$, with no equipment costs $(0 \%)$. Typical predatormanagement budgets allocated money for: Labor $(\approx 68 \%)$, vehicle operation $(\approx 12 \%)$, materials and supplies $(\approx 2 \%$ ), equipment $(\approx 1 \%)$, training $(\approx 1 \%)$, and overhead $(\approx 16 \%)$. 
Table 3 provides 2003 values (current) for the reproduction-monitoring and predator-management budgets during the study. Budgets were essentially stable, with only modest inflation-related increases. Summing the two budgets showed that 1998 and 1999 were the highest and lowest funded years, respectively. The highest budget year for reproduction monitoring was 1998 and the lowest was 1996. The highest predator-management budget occurred in 1996 and the lowest occurred in 1999. The high 1996 budget for predator removal can be explained partially by overtime pay policy; compensation time was provided in lieu of overtime during subsequent years to constrain costs.

Economic influences on the dependent variables were treated as proxy variables. Budget data were converted to personnel time (US\$ $/ \mathrm{h}$ ) spent monitoring reproduction or controlling predators. We created proxy variables because precise daily expenditures for labor costs were not recorded. However, the time and date that staff spent at the site were recorded precisely and could be converted to an hourly fee. Reproduction monitoring (Monitorhrs), predator management (Predhrs), and the composite of these (Totalhrs) were developed to reflect budgetary impacts on the dependent variables.

\subsubsection{Meteorological data}

Including meteorological variables in the system allowed for the identification of possible environmental stressors that were not addressed elsewhere in the analysis. Extreme precipitation was expected to correlate with flooding or standing water on beaches,

Table 3

Predator-removal and reproduction-monitoring budgets

\begin{tabular}{lllllll}
\hline Year & \multicolumn{2}{l}{ 2003 Dollars } \\
\cline { 2 - 7 } & $\begin{array}{l}\text { Predator } \\
\text { budget } \\
\text { (US\$) }\end{array}$ & Rank & $\begin{array}{l}\text { Monitor } \\
\text { budget } \\
\text { (US\$) }\end{array}$ & Rank & $\begin{array}{l}\text { Total } \\
\text { budget } \\
\text { (US\$) }\end{array}$ & Rank \\
\hline 1995 & 76,170 & 2 & 71,046 & 6 & 147,216 & 5 \\
1996 & 78,753 & 1 & 68,477 & 7 & 147,230 & 4 \\
1997 & 73,019 & 4 & 76,594 & 3 & 149,613 & 3 \\
1998 & 73,165 & 3 & 81,275 & 1 & 154,440 & 1 \\
1999 & 70,366 & 7 & 75,890 & 4 & 146,256 & 7 \\
2000 & 71,601 & 6 & 75,328 & 5 & 146,929 & 6 \\
2001 & 72,763 & 5 & 80,005 & 2 & 152,768 & 2 \\
\hline
\end{tabular}

a Adjusted for inflation. potentially destructive or toxic events for nests or foraging shorebirds.

Specific weather data for dates encompassing tern activity at the site were obtained from National Atmospheric and Oceanic Administration [NOAA] (1996-2001). Four independent variables were used to assess potential weather influences upon the reproduction variables: average daily precipitation (Precip; $\mathrm{cm}$ ), average daily air temperature (Avgairtemp; ${ }^{\circ} \mathrm{C}$ ), average daily wind speed (Avgwspd; km/h), and average daily dewpoint (Dewpt; ${ }^{\circ} \mathrm{C}$ ). Average values were used to reflect the average climatic conditions of the day. High and low temperatures were initially used in the analysis but decreased the explanatory power of the analysis, and were omitted in favor of average values and an alternate measure of meteorological extremes. To capture the effects of climatic extremes, the variable Bad Outcome was added for this purpose. This variable represented potential meteorological events that could significantly impact the terns.

\subsection{System}

Reproduction of California least terns at Camp Pendleton was viewed as a system of biological, economic, meteorological, and other unmeasured variables, with combinations of these variables influencing the number of terns observed (Fig. 2). That is, interactions among biological $\left(X_{\mathrm{B}}\right)$, economic $\left(X_{\mathrm{E}}\right)$, meteorological $\left(X_{\mathrm{M}}\right)$, and other $\left(X_{\mathrm{O}}\right)$ variables determine each of the four dependent reproduction variables (i.e., $Y_{\text {nests }}, Y_{\text {eggs }}, Y_{\text {fledglings }}$, and $Y_{\text {adults }}$ ). Observations for those dependent variables not used in a given regression equation were still included as independent variables for purposes of prediction. For example, if the number of adult terns observed was the dependent variable of concern, then nests, eggs, and fledglings became predictor variables for that analysis.

Arrows (Fig. 2) indicate the direction of the postulated impacts, with the dashed arrow indicating the effect of diverse "other" variables that were unavailable as data. While the overall influence of factors, such as fisheries resources, toxicological impacts, and catastrophic events (e.g., surge tide, red tide), were undoubtedly important to the observed number of terns, these effects could not be estimated for the current model. Our empirical analysis attempts to estimate the relative magnitudes of $X_{\mathrm{M}}, X_{\mathrm{E}}$ and $X_{\mathrm{B}-\mathrm{Y}}$ on 


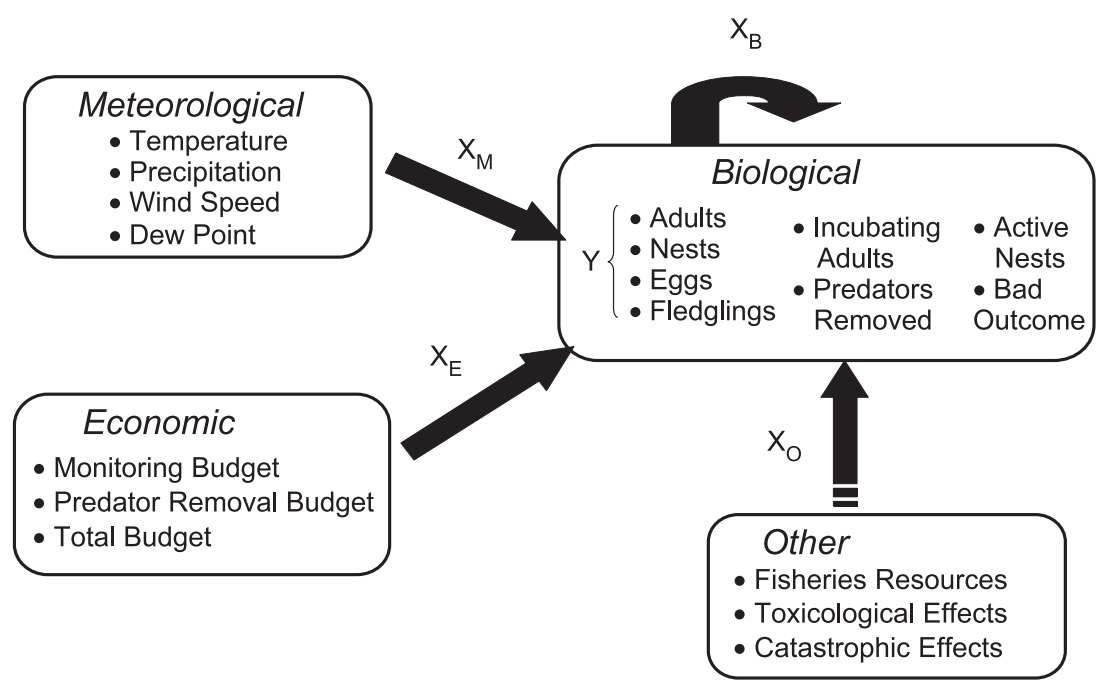

Fig. 2. Schematic of the Tern Reproduction System and interaction of biological, economic, meteorological, and other variables.

$Y$. That is, we are attempting to estimate the relative size of each of the arrows on $Y$ (Fig. 2).

The bio-econometric model representing the system can be written as:

$Y=\beta_{1}+\beta_{2} X_{\mathrm{B}-\mathrm{Y}}+\beta_{3} X_{\mathrm{M}}+\beta_{4} X_{\mathrm{E}}+u_{t}$

where $X_{\mathrm{B}-\mathrm{Y}}$ represents the biological variables in the system less the biological variable that is the dependent variable.

\subsection{Model and data analysis}

There were 354 observations in our sample. The observations reflect occurrence of reproduction monitoring activities during the seven successive years of April-August nesting seasons. Years were condensed to represent observations made during the breeding season, omitting days without a recorded observation. Therefore, each "year" consisted of approximately 50.5 days. A correlation analysis was used to examine the positive/negative agreement and magnitude of relationships between pairs of variables and assess theoretical concurrence of predicted relationships. The results of the correlation were then matched with the model selection criteria to determine the final number variables in the system.

Multiple regression analyses were computed using the cited independent variables and four dependent variables in the system. All variables were tested for stationarity, using the Augmented Dickey Fuller (ADF) and Phillips-Peron (PP) tests (Enders, 1995). All of the dependent variables were stationary at the level and the independent variables that were nonstationary were made difference stationary. In all of the regressions, the Akaike-Schwartz criterion was used as the model selection criteria (Enders, 1995).

\section{Results}

\subsection{Regression analysis}

Table 4 provides descriptive statistics for each of the 15 variables in the system. The results of the four separate regressions are given in Table 5. Shaded boxes indicate that the variable was lagged. One period in this model was $\approx 2$ days. Variables were lagged to reflect that their influence on contemporaneous dependent variables was exerted in earlier periods. Sample sizes were noticeably different than the number of observations as a result of missing data in some series and the inclusion of lagged variables. Lagged variables were determined by the results of the Akaike-Schwartz criteria.

\subsubsection{Biological variables $\left(X_{B}\right)$}

The biological variables provided a number of consistent predictive relationships in each of the four 
Table 4

Descriptive statistics for the variables per monitoring day

\begin{tabular}{lrr}
\hline Variables & Mean & S.D. \\
\hline Adults & 145.22 & 213.66 \\
Totnests & 318.98 & 363.17 \\
Eggs & 18.58 & 79.41 \\
Fledglings & 26.30 & 77.32 \\
Actnests & 73.91 & 150.74 \\
Adincub & 0.13 & 1.05 \\
Totalpred & 1.46 & 2.28 \\
Bad outcome & 0.22 & 0.42 \\
Predremhrs & 6.96 & 3.36 \\
Monitorhrs & 3.12 & 4.80 \\
Totalhrs & 12.00 & 27.60 \\
Precip & 0.03 & 0.17 \\
Avgairtemp & 18.05 & 14.58 \\
Avgwspd & 5.34 & 2.16 \\
Dewpt & -10.83 & 15.88 \\
\hline
\end{tabular}

equations. Although some disparities in the sign and lack of significance for certain coefficients occurred, the main reproduction variables of Adults, Totnests, Eggs, and Fledglings generally were related and predictive of observed counts for the other dependent variables when used as regressors. Moreover, counts of active nests (Actnests) and adult birds sitting on nests (Adincub) proved predictive of Eggs and Fledglings (i.e., negative sign showed that incubation decreased as chicks began to fly). Together, the pattern of coefficients generally attests to the strong relationships of these variables, and the strong interdependencies among diverse factors reflective of reproduction in the terns.

Highlights of key biological effects evident in the regression analyses showed that number of adult terns (Adults) was an important, positive predictor in the $Y_{\text {nests }}$ equation and the $Y_{\text {eggs }}$ equation. Not surprisingly, this demonstrated that Adults were important to observations of Totnests and Eggs. Adults yielded no prediction (though a positive coefficient) in the $Y_{\text {fledglings }}$ equation. It must be noted that a hierarchy of counting accuracy is undoubtedly present in observational counts of the four dependent variables, with Totnests, Actnests, and Eggs the most definitive counts, and with Fledglings and Adults posing greater measurement

Table 5

Coefficients of separate regression analyses using four dependent variables $Y_{\text {nests }}, Y_{\text {eggs }}, Y_{\text {fledglings }}$, and $Y_{\text {adults }}$ (standard error); shaded areas represent lagged variables

\begin{tabular}{|c|c|c|c|c|}
\hline \multirow[t]{2}{*}{ Independent variables } & \multicolumn{4}{|c|}{ Dependent variables/development stage } \\
\hline & Adults & Total nests & Eggs & Fledglings \\
\hline Constant & $4.92(35.44)$ & $-195.056(78.91)$ & $35.47(27.7)$ & $-14.13(8.70)$ \\
\hline Actnests & $0.144 * *(.065)$ & - & $1.43 *(.05)$ & $-0.151 *(.02)$ \\
\hline Adincub & $3.14(5.56)$ & $-5.20(12.47)$ & $38.64 *(4.98)$ & $4.24 *(1.63)$ \\
\hline Adults & - & $.267 * *(.131)$ & $.09 * *(.05)$ & $0.013(.015)$ \\
\hline Totnests & $.203 *(.03)$ & - & $-.107(.02)$ & $.075^{*}(.007)$ \\
\hline Eggs & $-.086 * *(.036)$ & $.73 *(.055)$ & - & $0.004(.008)$ \\
\hline Fledglings & $.359 * *(.208)$ & $4.34 *(.49)$ & $0.022(.167)$ & - \\
\hline Totalpred & $0.47(1.11)$ & $-.33(2.58)$ & $-.33(.89)$ & $0.14(.28)$ \\
\hline Bad outcome & $-5.79(10.68)$ & $-31.43(24.68)$ & $-11.05(8.63)$ & $-3.71(2.69)$ \\
\hline Predremhrs & $9.59(19.51)$ & $39.37(45.21)$ & $4.479(16.22)$ & $-13.18^{* *}(5.19)$ \\
\hline Monitorhrs & $35.2(40.47)$ & $35.84(79.47)$ & $35.98(27.64)$ & $26.43 * *(12.16)$ \\
\hline Totaltime & $8.97 * * *(5.02)$ & $9.2(11.80)$ & $0.128(4.31)$ & $4.43 *(1.34)$ \\
\hline Precip & $-8.75(23.78)$ & $14.16(54.43)$ & $-7.25(19.022)$ & $1.3(6.08)$ \\
\hline Avgairtemp & $-0.79(.84)$ & $2.95(1.90)$ & $-0.44(.65)$ & $0.12(.21)$ \\
\hline Avgwspd & $1.2(1.76)$ & $2.63(4.07)$ & $-1.70(1.41)$ & $-0.49(.45)$ \\
\hline Dewpt & $0.789(.64)$ & $0.111(1.46)$ & $-.116(.51)$ & $0.23(.16)$ \\
\hline Sample size & 236 & 235 & 235 & 236 \\
\hline AIC & 10.05 & 11.69 & 9.60 & 7.31 \\
\hline SBC & 10.27 & 11.9 & 9.81 & 7.52 \\
\hline$R^{2}$ & 0.52 & 0.66 & 0.93 & 0.54 \\
\hline
\end{tabular}

\footnotetext{
* Significant at the $1 \%$ level.

** Significant at the $5 \%$ level.

*** Significant at the $10 \%$ level.
} 
difficulties due to flight. Totnests was important in the $Y_{\text {adults }}$ and $Y_{\text {fledglings }}$ equations. All coefficients were positively related to these dependent variables. This positive relationship between Totnests and adults reflects the fact that an increase in the total number of nests observed is in part a reflection of an increase in the number of adults creating those nests. The positive nature of the relationship between Totnests and fledglings indicates that more nests will most likely lead to a greater yield of fledglings.

\subsubsection{Economic variables $\left(X_{E}\right)$}

Results for the economic variables indicated that Monitorhrs was a key, positive predictor for $Y_{\text {fledglings, }}$, and that Predremhrs also accounted for sizable variance in predicting $Y_{\text {fledglings }}$ (negative coefficient). In short, the greater monitoring dollars invested in hours used to measure tern reproduction, the more Fledglings counted. Totalhrs yielded a strong positive relationship with $Y_{\text {fledglings }}$ and $Y_{\text {adults. }}$. We contend that these proxy variables reflecting labor costs indicate that both reproduction monitoring and predator removal time are crucial to the observance of greater numbers of Fledglings and Adults.

Predremhrs was important and negative in the $Y_{\text {fledglings }}$ equation. Although coefficients were negative for fledglings, this is probably due to the difficulty in protecting new-flying terns from predators (especially avian predators). When predation of fledglings occurred, personnel could expend significant amounts of time trying to remove predators to protect this dwindling age class. Counts of terns at this stage of development are tenuous and may have produced simply no consistent pattern of relationship between fledgling counts and staff hours spent in predator removal activities.

\subsubsection{Meteorological $\left(X_{M}\right)$}

The meteorological variables were of minimal importance in accounting for observational counts at any developmental stage (Adults, Nests, Eggs, or Fledglings). This result is surprising in that meteorological effects are generally thought to play an important role in the terns' reproductive success. Descriptive statistics (Table 4) for these variables also suggested that weather conditions were generally mild and stable across years and seasons. However, the mean values of variables often obscure the importance of brief, within-day wind gusts, tidal events, and other negative weather events.

\subsection{Forecast analysis}

The regression analysis identified and measured the effects of the independent variables $\left(X_{\mathrm{B}}, X_{\mathrm{M}}\right.$, and $X_{\mathrm{E}}$ ) on the dependent variables ( $Y_{\text {adults }}, Y_{\text {totnests, }}, Y_{\text {eggs }}$, and $Y_{\text {fledglings }}$ ) and this relationship can be used to project future values of the dependent variables. The regression analysis was used to obtain the estimates of the coefficients, and from this we were able to formulate equations to forecast the number of adults, nests, eggs, and fledglings, given fixed increases of $25 \%, 50 \%$, and $100 \%$, in the $X_{\mathrm{E}}$ variables.

We performed analysis of four separate equations for each of our dependent variables. In each equation, we used the mean values of the biological and meteorological variables and scaled up each of the economic variables independently. Initially, it was expected that increasing the total hours would cause the greatest benefit to production for each development stage since total hours is simply monitoring hours plus predator-removal hours. However, the results of the forecast analysis clearly showed that the relationship between dependent variables and the economic variables is a dynamic process that changes with development stages.

Total nests and fledglings were influenced most by monitoring hours. Even 25\% increased funds for this activity was forecasted to yield $105.6 \%$ and $38.6 \%$ more nests and fledglings counts, respectively (Table 6). New nests lack prey items so it is not necessary for predator removal staff to invest more time in protecting these nests until the presence of eggs. However, monitors invest many hours in the discovery and recording of new nests. The importance of monitoring hours in forecasting total nests confirms that monitoring pays big dividends for finding nests and counting elusive young birds.

Predator removal hours were forecasted to yield the greatest return for producing future numbers of eggs. In this case, a $25 \%$ increase in funding for predatorremoval hours produces $10.4 \%$ more eggs. This effect could be due to the long-lasting impact or initial removal of resident predators, because time is required for the ingress of predators which coincides 
Table 6

Percent increase forecast for the dependent variables as a result of an increase in the independent variables

\begin{tabular}{|c|c|c|c|c|c|c|c|c|c|}
\hline \multirow{3}{*}{$\begin{array}{l}\text { Development stage/ } \\
\text { dependent variable }\end{array}$} & \multicolumn{9}{|c|}{ Scaled independent variable } \\
\hline & \multicolumn{3}{|c|}{ Monitor hours (\%) } & \multicolumn{3}{|c|}{ Predator-removal hours (\%) } & \multicolumn{3}{|c|}{ Total hours $(\%)$} \\
\hline & 25 & 50 & 100 & 25 & 50 & 100 & 25 & 50 & 100 \\
\hline Adults & 7.6 & 14.1 & 24.7 & 4.8 & 9.1 & 16.7 & 8.1 & 16.1 & 32.2 \\
\hline Total nests & 105.6 & 211.5 & 423.2 & 29.1 & 58.4 & 117.1 & 1.2 & 2.6 & 5.5 \\
\hline Eggs & 4.2 & 8.5 & 16.9 & 10.4 & 20.8 & 41.5 & 4.2 & 8.4 & 16.7 \\
\hline Fledglings & 38.6 & 77.2 & 154.3 & -42.9 & -85.8 & -171.7 & 24.9 & 49.8 & 99.5 \\
\hline
\end{tabular}

with nesting and egg laying. Prior to the arrival of the terns, predator removal is important to prepare the site and provide some predator removal for protection of the adults upon arrival. However, as the site evolves and nests are formed, there is less of a role for predator-removal staff until prey items (i.e., eggs) are available in the nests. When eggs are available for predators in the nests, the efforts of predator-removal staff again become crucial to the protection of eggs.

The difficulty in protecting fledglings is reflected by the negative sign on the coefficient for predatorremoval hours in the fledgling forecast. Fledglings are mobile, erratic, and vulnerable to a multitude of predators; this makes protection complex and time consuming. In many cases, predator-removal staff increases their daily work hours, but remove fewer predators. This explains the negative relationship between forecasts of greater funds for predator removal hours and the fledgling's variable.

Finally, total hours was the most influential in forecasting the future number of adults, but less influential in the other three equations. Specifically, a $25 \%$ increase in the funding of both monitoring and predator-removal hours yields an $8.1 \%$ increase in the production of adults. Theoretically, this makes sense. Both monitoring and predator-removal staff invest an intensive amount of time prior to the arrival of adults. During this time, staff prepares the site through habitat management, mark the nest areas, erect protective barriers, and remove resident predators.

\section{Discussion}

This study sought to determine whether reproduction-monitoring and predator-management budgets affect the observed number of tern adults, nests, eggs, and fledglings. If we accept the premise that proxy hours for these budgets are valid indices of fiscal effects, the current results support this contention. In all cases, except for predator-removal time as a regressor of numbers of nests and fledglings, the proxy variables were associated with greater counts of the dependent variables. This is indirect evidence of increased production based on increased budgets. At the very least, these economic variables appear to be as potent as selected biological variables and more potent than selected meteorological variables in accounting for variance in diverse measurements of California least tern reproduction.

Although numerous studies have attempted to provide benefit-cost analyses of TS/ES expenditures, most have involved largely theoretical treatises of citizens" "willingness-to-pay" for intrinsic, nonconsumptive uses of wildlife (e.g., Boyle and Bishop, 1987; Loomis and Ekstrand, 1997; Whitehead, 1992) or alternate measures of cost-utility analysis (Cullen et al., 2001). The current study differs from much prior research because it provides an empirical analysis of actual fiscal data involved in the protection of a recognized ES. A 1997 report by the Majority Staff of the U.S. House of Representatives estimated total spending by all federal agencies related to TS/ES for that year at US\$501,625,000 (Office of the Chief Counsel, 1998). Our data reveal that $>$ US $\$ 1.04$ million (net current value) was spent to recruit California least terns at Camp Pendleton during 1995-2001; while estimates of adult terns during this period increased from 363 to 993 adult pairs - a rough tripling of nesting pairs for the investment (Foster, 1996, 2002).

The forecasted results are consistent with the role of the economic variables at each reproductive stage. In particular, to increase the number of adults 
observed, it is most effective to increase the total time spent at the site (monitor hours plus predator-removal hours), which reflects that monitoring and predatorremoval staff are heavily involved in the preparation of the site prior to the arrival of adults. Increasing the number of monitoring hours is the most efficient way to increase the future number of total nests observed, or in other words, the more time that monitors spend in the field, the greater the number of nests detected. Later in the season, as eggs are more prevalent at the site, the work of predator-removal staff becomes increasingly important to protect the eggs, which indicates that the effectual way to increase the number of eggs is to increase the number of predator-removal hours. As the eggs become fledglings, and have some limited defense against predators, the role of monitors was again the most crucial factor among the economic variables in determining future values of fledglings.

The lack of importance of the meteorological variables in predicting the dependent variables warrants comment. We believe that the use of dummy variables or improved ways of deriving variables that reflect short-term, disastrous environmental consequences is important. Annually, some nests, eggs, and chicks are lost to high tides, rainfall-induced flooding of localized nest areas, etc. (Foster, 2002). Our use of daily meteorological variables probably attenuated these effects. Future analyses of TS/ES recruitment need to include improved quantifiable indices of potential catastrophic meteorological incidents upon dependent variables.

In conclusion, our results are part of a growing body of literature that attests to the benefits of active predator management as a means of enhancing recruitment of TS/ES (Butchko, 1990; Butchko and Small, 1992; Engeman et al., 2002). Except for the potential of fencing to deter some human and predator encroachment at nest sites in this study, the active removal of predators was associated with the resultant prediction of increased adults and eggs; this convinces us that predator management is crucial to recruitment. Although reproduction monitoring appeared to be more influential in predicting adults, eggs, and fledglings, monitoring is a passive, surveillance-type activity. Predator management was the main active, wildlife-intervention activity involved in this study. As we discussed, monitoring also helps to focus predator-management activities.

\section{Acknowledgments and Disclaimer}

We thank the U. S. Navy Facilities Engineering Command (NAVFAENGCOM), Natural Resources Branch, Southwest Division, San Diego, CA and the Resources Management Division, Assistant Chief of Staff (AC/S), Environmental Security, U. S. Marine Corps Base, Camp Pendleton, CA (USMCBCP) for support of the California Least Tern Program and for permission to publish these data. In particular, we acknowledge Tim Burr (NAVFAENGCOM) for providing budgetary data used in this paper. Additionally, we thank Tim Burr, William Berry (USMCBCP), Carie Dann (PFA), Robert Lovich (USMCBCP), Richard Engeman (USDA), Thomas Hoffman (USDA), and Kathleen Fagerstone (USDA) for critical reviews of the draft manuscript.

Use of trade names does not constitute endorsement by the federal government.

\section{References}

Avery, M.L., Pavelka, M.A., Bergman, D.L., Decker, D.G., Knittle, C.E., Linz, G.M., 1995. Aversive conditioning to reduce raven predation on California least tern eggs. Colon. Waterbirds 18 (2), 131-138.

Bent, A.C., 1921. Life histories of North American gulls and terns. U. S. Nat. Hist. Mus. Bull. 113.

Boyle, K.J., Bishop, R.C., 1987. Valuing wildlife in benefit-cost analyses: a case study involving endangered species. Water Resour. Res. 23 (5), 943-950.

Butchko, P.H., 1990. Predator control for the protection of endangered species in California. Proc., Vertebr. Pest Conf. 14, 237-240.

Butchko, P.H., Small, M.A., 1992. Developing a strategy of predator control for the protection of the California least tern: a case history. Proc., Vertebr. Pest Conf. 15, 29-31.

Caffrey, C., 1994. California least tern breeding survey. 1993 season. Nongame Bird and Mammal Conservation Program Rep, vol. 94-3. California Dept. Fish and Game Wildl. Manage. Div, Sacramento, California. 49pp.

Cullen, R., Fairburn, G., Hughey, K.F.D., 2001. Measuring the productivity of threatened species programs. Ecol. Econ. 39, $53-66$.

Enders, W., 1995. Applied Econometric Time Series. John Wiley and Sons, New York.

Engeman, R.M., Shwiff, S.A., Constantin, B., Stahl, M., Smith, H.T., 2002. An economic analysis of predator removal approaches for protecting marine turtle nests at Hobe Sound National Wildlife Refuge. Ecol. Econ. 42, 469-478.

English, A.G. 1999. Predator management report for Marine Corps Base, Camp Pendleton Oceanside, California: 1999 California 
least tern and Western snowy plover breeding season. Unpublished report prepared for the Natural Resources Management Branch, Southwest Division Naval Facilities Engineering Command, San Diego, California. U. S. Department of Agriculture, Wildlife Services, El Cajon, California. 7pp.

Federal Register, 1970. List of Threatened Fauna and Flora in the United States 35, pp. 8491-8498.

Foster, B.D. 1996. Breeding status of the California least tern at Marine Corp Base, Camp Pendleton, California, 1995. Unpublished report prepared for the Natural Resources Management Branch, Southwest Division Naval Facilities Engineering Command, San Diego, California. 176pp.

Foster, B.D. 1997. Breeding status of the California least tern at Marine Corp Base, Camp Pendleton, California, 1996. Unpublished report prepared for the Natural Resources Management Branch, Southwest Division Naval Facilities Engineering Command, San Diego, California. 53pp.

Foster, B.D. 1998. Breeding status of the California least tern at Marine Corp Base, Camp Pendleton, California, 1997. Unpublished report prepared for the Natural Resources Management Branch, Southwest Division Naval Facilities Engineering Command, San Diego, California. 114pp.

Foster, B.D. 1999. Breeding status of the California least tern at Marine Corp Base, Camp Pendleton, California, 1998. Unpublished report prepared for the Natural Resources Management Branch, Southwest Division Naval Facilities Engineering Command, San Diego, California. 112pp.

Foster, B.D. 2000. Breeding status of the California least tern at Marine Corp Base, Camp Pendleton, California, 1999. Unpublished report prepared for the Natural Resources Management Branch, Southwest Division Naval Facilities Engineering Command, San Diego, California. 111pp.

Foster, B.D. 2001. Breeding status of the California least tern at Marine Corp Base, Camp Pendleton, California, 2000. Unpub- lished report prepared for the Natural Resources Management Branch, Southwest Division Naval Facilities Engineering Command, San Diego, California. 122pp.

Foster, B.D. 2002. Breeding status of the California least tern at Marine Corp Base, Camp Pendleton, California, 2001. Unpublished report prepared for the Natural Resources Management Branch, Southwest Division Naval Facilities Engineering Command, San Diego, California. 128pp.

Grinnell, J., Miller, A.H., 1944. The distribution of the birds of California. Pac. Coast Avifauna 27, 1-608.

Hyngstrom, S.E., Timm, R.M., Larson, G.E. (Eds.), Prevention and Control of Wildlife Damage, (2nd Edition) Great Plains Agricultural Council: Lincoln, Nebraska. (2 v (loose leaf)).

Loomis, J.B., Ekstrand, E., 1997. Economic benefits of critical habitat for the Mexican Spotted Owl: a scope test using a multiple-bounded contingent valuation survey. J. Agric. Resour. Econ. 23 (2), 356-366.

Massey, B.W., Fancher, J.M., 1989. Renesting by California least terns. J. Field Orinthol. 60, 350-357.

National Oceanic and Atmospheric Association (NOAA, 19962001),www.noaa.com.

Secrist, E.E., 1915. Least tern. Ocologist 32, 18.

U.S. Department of the Interior, 1973. Threatened Wildlife in the United States. Resource Publication 114. Bureau of Sports Fisheries and Wildlife, Washington, D.C., pp. 153-154.

U.S. Office of the Chief Counsel, 1998. The Endangered Species Act: How Much Does it Cost the taxpayer? Office of the Chief Counsel, Washington, DC. 15pp.

Whitehead, J.C., 1992. Ex ante willingness to pay with supply and demand uncertainty: implications for valuing a marine turtle protection programme. Appl. Econ. 24, 981-988. 